\title{
Long Flat Continuous Conveyors without Critical Transfer Points
}

\author{
Eric Penno*, Sebastian Weise, Markus Golder \\ Professorship of Conveying Engineering and Materials Handling, Chemnitz University of Technology, Germany \\ * Correspondence: eric.penno@mb.tu-chemnitz.de
}

Received 2 November 2020; Accepted 3 November 2020; Available online 7 December 2020

(C) 2020 by E. Penno et al. This is an open access article distributed under the Creative Commons Attribution License (CC-BY 4.O), which permits unrestricted use, distribution, and reproduction in any medium, provided the original work is properly cited.

\begin{abstract}
Conventionally, a series of several individual conveyors is necessary to realise long conveyor lines. This segmentation creates critical transfer points for the transport of goods. The number of transfer points and the overall height can be minimised by direct drives based on magnetic toothed belts and carriers attached to the mat chains. For example, a modular belt conveyor with an overall height of $100 \mathrm{~mm}$ and a width of $1 \mathrm{~m}$ can reach a length of well over $10 \mathrm{~m}$. The friction between the mat chain and the sliding plane can be reduced by using alternative sliding partners such as a textile or a sliding support made of wood-based materials. These measures increase process and work safety and allow the system to be designed to be energy efficient.
\end{abstract}

KEYWORDS direct drive, continuous conveyor, magnetic toothed belt, technical textile, sliding support

\section{Introduction}

Drives for belt conveyor systems and modular conveyor systems established on the market are mostly head drives or centre drives. In most cases, the endlessly connected traction and load-bearing elements are positively driven at the head of the conveyor by sprockets. The support of the mat chains is currently mostly sliding by means of strips or plates made of plastic, stainless steel or laminated wood. Existing conveyor systems are usually limited in their overall height and length depending on the weight of the material to be conveyed, by the size of the motor and the maximum chain tensile forces. [1] [2].

For the belt and modular belt conveyor systems established on the market, the overall heights are related to the distance between the upper and lower run (Figure 1) [3] For use in limited installation space or at floor level, the actual overall height including drive is decisive. In conventional long conveyor systems, individual conveyors are connected in series. This is necessary because the maximum chain tensile forces at the head drive limit the length. [4] The individual conveyors are each equipped with their own drives. This requires a large number of critical fixed transfer points to bridge the gaps that arise (see Figure 2). 


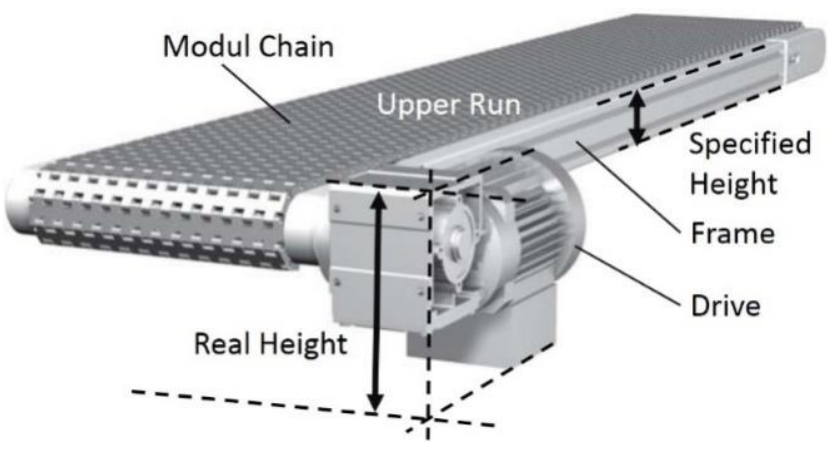

Figure 1: Overall heights on single conveyors with modular chain [3]
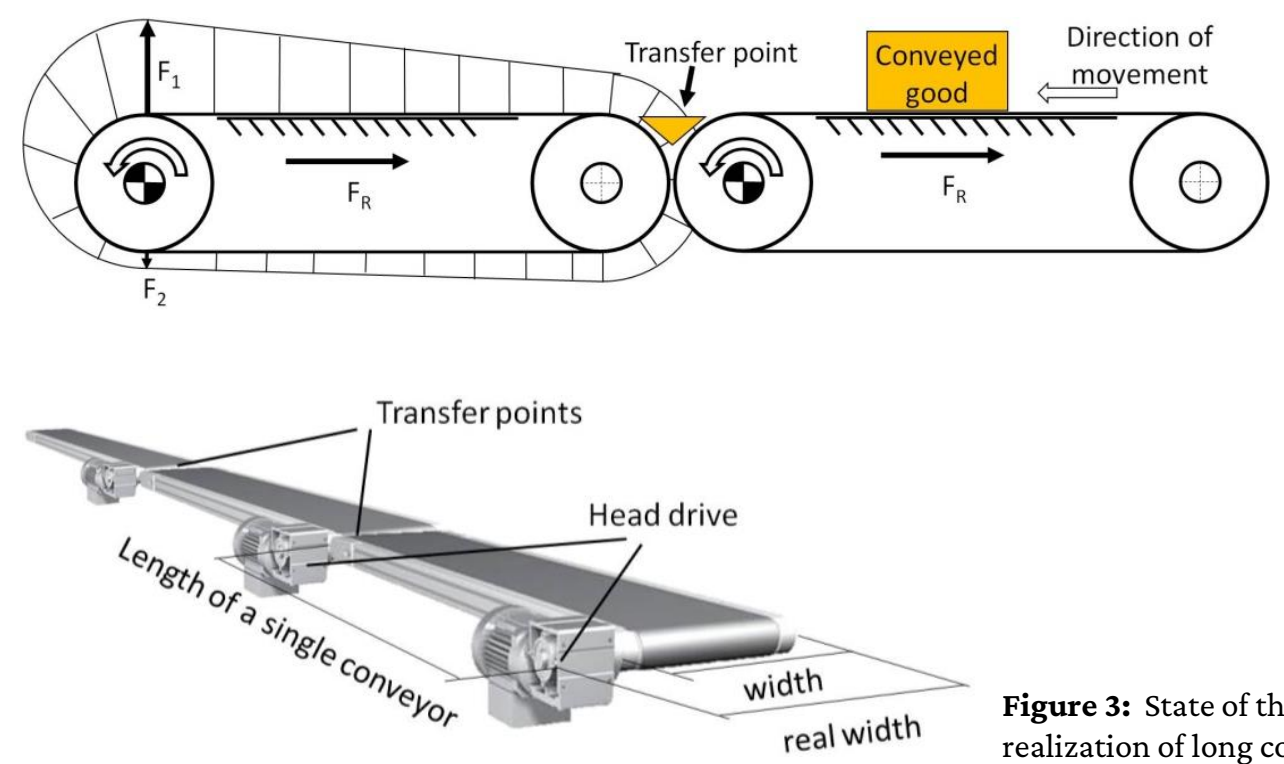

Figure 2: Tractive force curve in headside driven conveyor systems with circulating traction or load-bearing means [2]

\section{State of the Art}

Figure 3 shows the state of the art schematically with three individual conveyors connected in series with head drive and two resulting critical transfer points. The size of the motor indicates the actual height and width, which are decisive for the installation, especially for variants close to the floor and space-saving variants. In the event of a drive failure, a section of the conveyor line stands still and the material flow is interrupted.

Figure 4 illustrates the use of existing systems. It shows several worker conveyors connected in series with an internal head drive. The dimensions of the individual modules are limited in length and width by the chain traction force that occurs, which causes the critical transfer points. These points, which are fixed in relation to the relatively moving belt, pose risks to work safety and production reliability.

An existing concept of the TU Chemnitz is the direct drive via magnetic toothed belts. [5] Here, two identical magnetic toothed belts are driven synchronously. The drive power is provided by two space-intensive, synchronously running geared motors or by connecting 


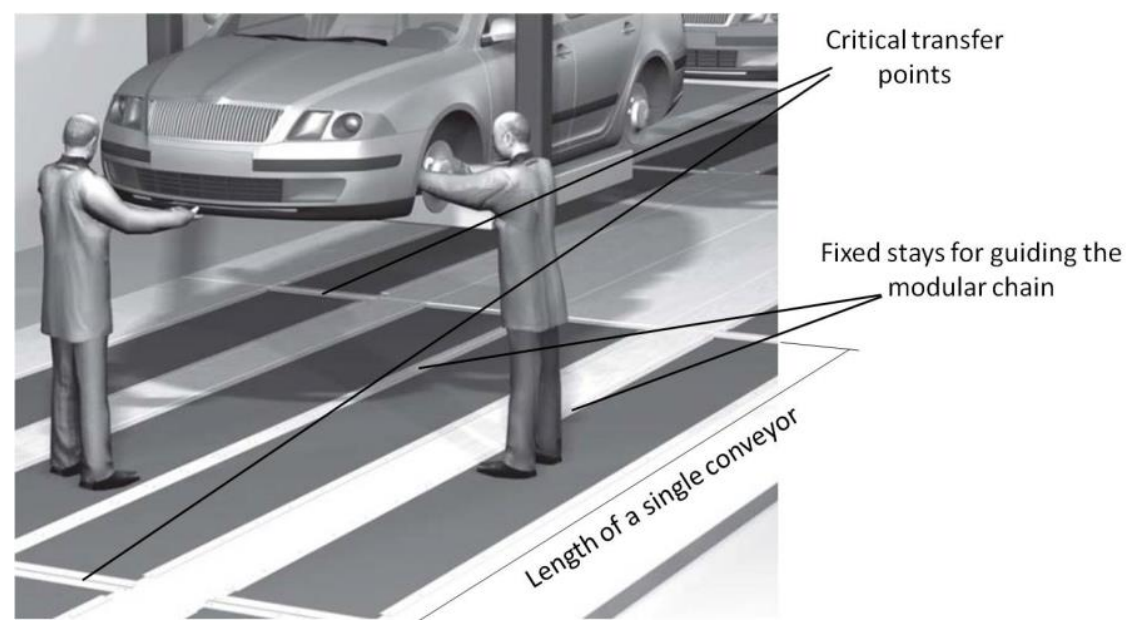

Figure 4: Conveyor system in serial connection with critical transfer points [3]

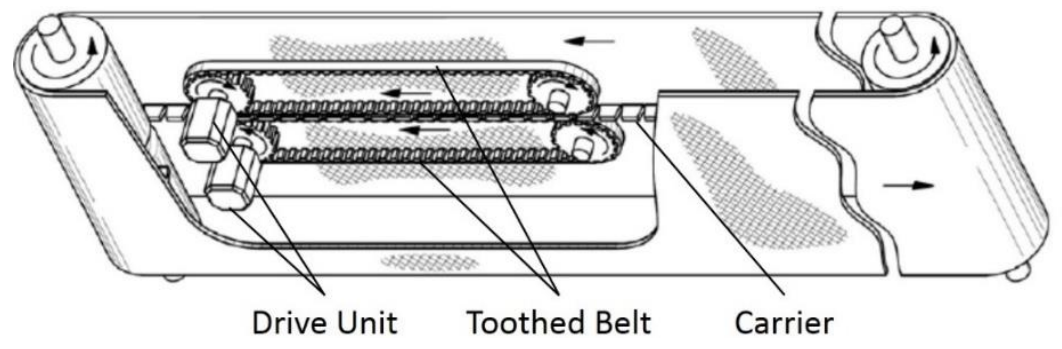

Figure 5: Direct drive on belt conveyor [4]

the two toothed belt wheels by means of gear and bevel gear units with a large motor. The chain movement is made possible by clamping the carriers between the magnetic toothed belts and their rotational movement. Real implementations prove the functionality, but also show that the implementation with the conventional drive concepts of the magnetic toothed belts for a flat, high-performance design is not possible with the classic structure of a directly attached drive. [4] The principle in Figure 5 is based on two synchronously driven, tightening toothed belts. These set the belt in motion by means of attached carriers via frictional and positive locking.

\section{Definition of the Problem}

Due to the many fixed transfer points between the individual conveyors, a continuous transfer of the conveyed material from one conveyor element to another is not always guaranteed. When transporting people, such as on an assembly conveyor belt in the automotive industry or in transfer operations at airports, these transfer points pose a risk of injury to persons. Therefore, a conveyor line should be designed with an uninterrupted traction and carrying means. However, this leads to an increase in the tractive forces on the load-bearing element. This results in a higher necessary performance. The problem with existing drive types is the introduction of the force as a compact power density via a single drive per conveyor belt. If a lot of power is required, this means a large motor. The length or diameter of this motor has a decisive influence on the actual height. Furthermore, the drive shaft of head drives is mechanically stressed by higher tensile forces. This results in excessive 
wear of the drive wheels, skipping of the chain or failure of the system during operation. This can be counteracted by increasing the rigidity of the shaft. This requires an increase in dimension or mass.

A further difficulty is that the currently available direct drive with magnetic toothed belt leads to a forced positioning of the belts. The magnets integrated in the toothed belt cannot be optimally aligned with each other. Therefore, the highest possible drive torque cannot be transmitted. Due to the conventional drive-side design with a gearbox, a large distance between upper and lower run is required for power transmission.

\section{Innovative Modular Belt Conveyor System}

The direct drive via magnetic toothed belts is driven on one side for the first time in this new type of continuous conveyor. This avoids the forced positioning of the magnets as with the double-sided magnetic toothed belt pairing. Furthermore, complexity is reduced and a flat design is achieved. Several individually used drives are direct drives as shown in Figure 6 between the upper and lower run form the so-called multipoint drive. This is a drive with several points of action within one system. The drive module is also energy efficient due to the individual positioning directly at the point of action. This means that the power in a certain area can be introduced into the system in a compact form as shown in Figure 7.

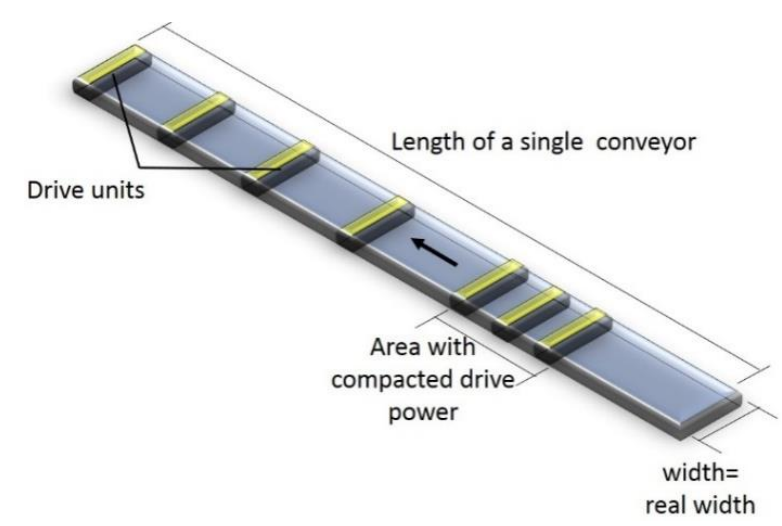

Figure 6: Modular belt conveyor system (schematic)

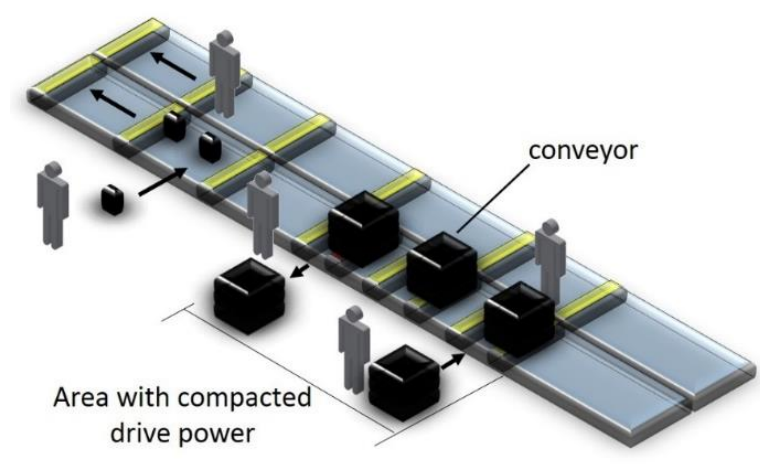

Figure 7: Parallel modular belt conveyor systems with compressed power range

\section{Development of the Carriers}

The carriers are the link between the conveyor chain and the drive. The original fin-shaped carriers from the TU Chemnitz concept of direct drive via magnetic timing belts have been further developed. [4] These rigid carriers could not be used for an ultra-flat design. The fins standing perpendicular to the mat chain greatly restricted the cross-section of the necessary crossbars. They also limited the deflection radius at the head end. Due to the direct drive concept, the deflectors no longer have a drive function. They no longer transmit any torque 

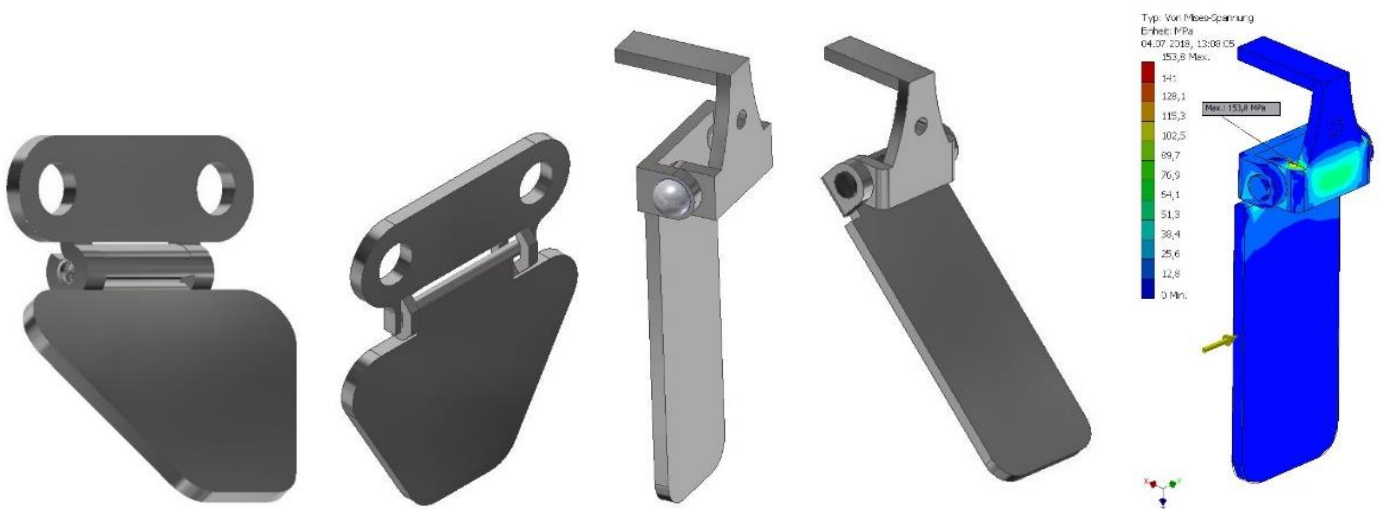

Figure 8: Development of the foldable carrier

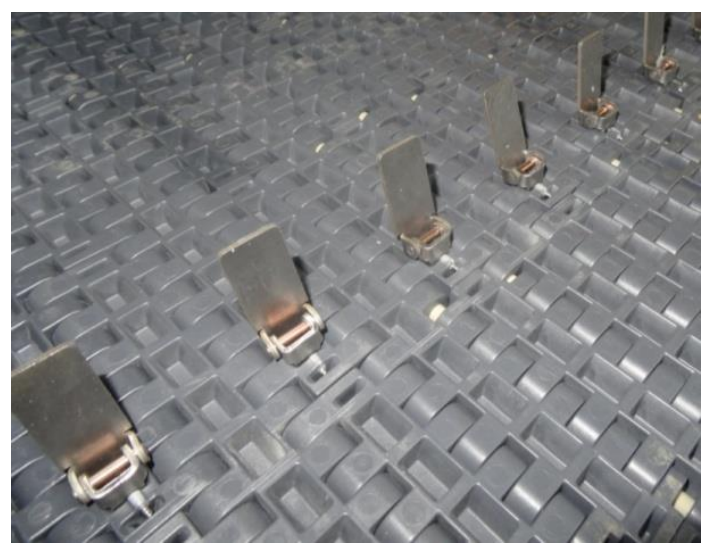

Figure 9: Prototype status of the foldable carriers on the mat chain

into the system and thus only take over the function of axes. The original drive wheels now only have the function of a guide instead of a force transmission. Due to this reduction of tasks, they can be dimensioned smaller.

A successive further development of the fin, which is rigidly fixed to the mat chain, resulted in a folding carrier. This made it possible to reduce the inner diameter of the return from $100 \mathrm{~mm}$ to $65 \mathrm{~mm}$. In addition, a stable cross beam for the frame of a modular belt system with sufficient stiffness can be developed.

The developed fins allowed a connection to existing, commercially available mat chain links. In the future, these are to be integrated into the mat chain links during production.

\section{Carrier-Belt Relationship}

The basic principle is the magnetic attraction force $F_{M}$ between the magnets of two opposite belts, as well as the magnetically acting attraction force on the carriers and the static friction value between carrier and magnetic toothed belt (Figure 10). The transmittable conveying force $F$ corresponds to the counteracting frictional force $F_{R}$ resulting from the static friction value and the clamping force. 
The magnets are embedded in the toothed belt. They are covered by a polyurethane (PU) layer $(0.6 \mathrm{~mm})$ and a silicone layer $(0.4 \mathrm{~mm})$. The silicone is necessary for a better adhesion to the ferritic steel carriers. The determined coefficient of friction with the friction partner steel is 0.8 . A calculation model for the holding force was created for the magnetic force that occurs. As the field density decreases with increasing distance from the magnet, the holding force acting on the carrier also decreases. Due to the necessary covering with PU and the silicone layer, a distance of $1 \mathrm{~mm}$ is forced between magnet and carrier. The model results in a holding force per carrier of $5.2 \mathrm{~N}$. In addition, the actual attraction force of two magnets was determined. If there is a carrier between the two magnets, a distance of $3.5 \mathrm{~mm}$ results with a magnetic attraction force of $2.5 \mathrm{~N}$. However, the carrier is saturated by the magnetic effect, so that only fractions of this attraction are effective. If no carrier is engaged, a distance of $2 \mathrm{~mm}$ results with an attractive force of $4.522 \mathrm{~N}$. Experimentally determined pull-off forces of the carriers per magnet were on average $6 \mathrm{~N}$. The carrier had a width of $15 \mathrm{~mm}$ and a thickness of $1.5 \mathrm{~mm}$. The reason for the difference to the model value of $5.2 \mathrm{~N}$ is the model assumption. The calculation refers to a magnetized area of $10 \mathrm{~mm} \times 5 \mathrm{~mm}$. In the real case the field lines of the magnet act through the distance on a larger area of the driver, which is $15 \mathrm{~mm} \times 35 \mathrm{~mm}$ in the effective area.

From the mathematical and experimental development of the holding force of a magnet on a carrier, conclusions were drawn about pairs of magnets acting on both sides of a carrier. This results in a transferable force per driver of $8.3 \mathrm{~N}$. In an experimental test, different material thicknesses of the drivers of $0.5 \mathrm{~mm}, 1 \mathrm{~mm}, 1.5 \mathrm{~mm}, 2 \mathrm{~mm}$ and $2.5 \mathrm{~mm}$ were examined. On the other hand, the distance between the drivers was varied between $10.4 \mathrm{~mm}, 35.8 \mathrm{~mm}$ and $61.2 \mathrm{~mm}$, which corresponds to the fixing of the carriers at the distance of the module chain links. The effect of synchronously driven toothed belt pairs on a single-sided driven toothed belt was also examined, as was the allocation, i.e. the distance between the flights. From the point of view of material and production, the materials bright steel and galvanized steel were investigated as carriers (Figure 12). The result was an optimum with a $1.5 \mathrm{~mm}$ thick untreated steel carrier. The spread of comparable carriers made of galvanized steel is too wide for the application. These carriers are mounted in the single pitch of the mat chain used. Due to the toothed belt drive, a tensile force of $800 \mathrm{~N}$ per

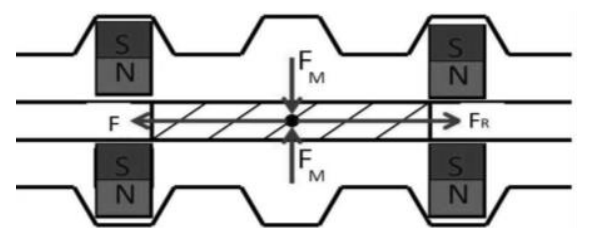

Figure 10: Principle of the forces

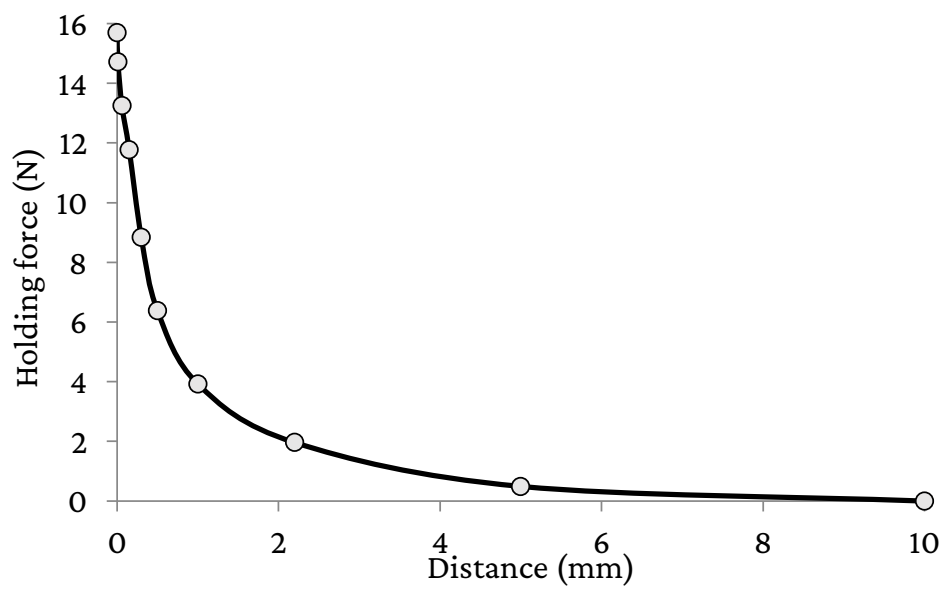

Figure 11: Magnetic force related to the distance of the carrier with thickness $1 \mathrm{~mm}$ 


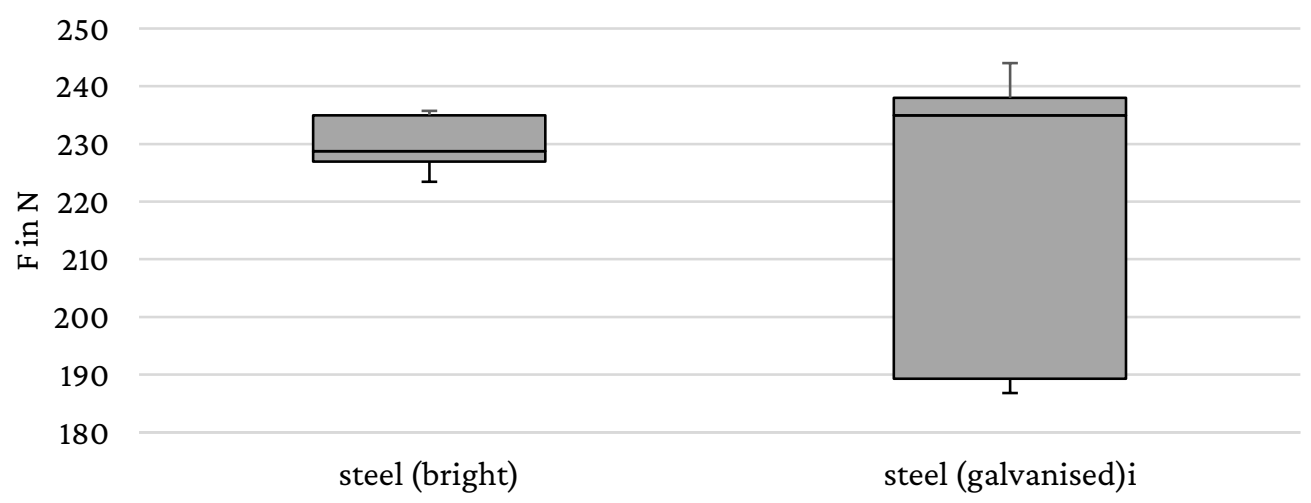

Figure 12: Comparison of the transmittable force of the carriers

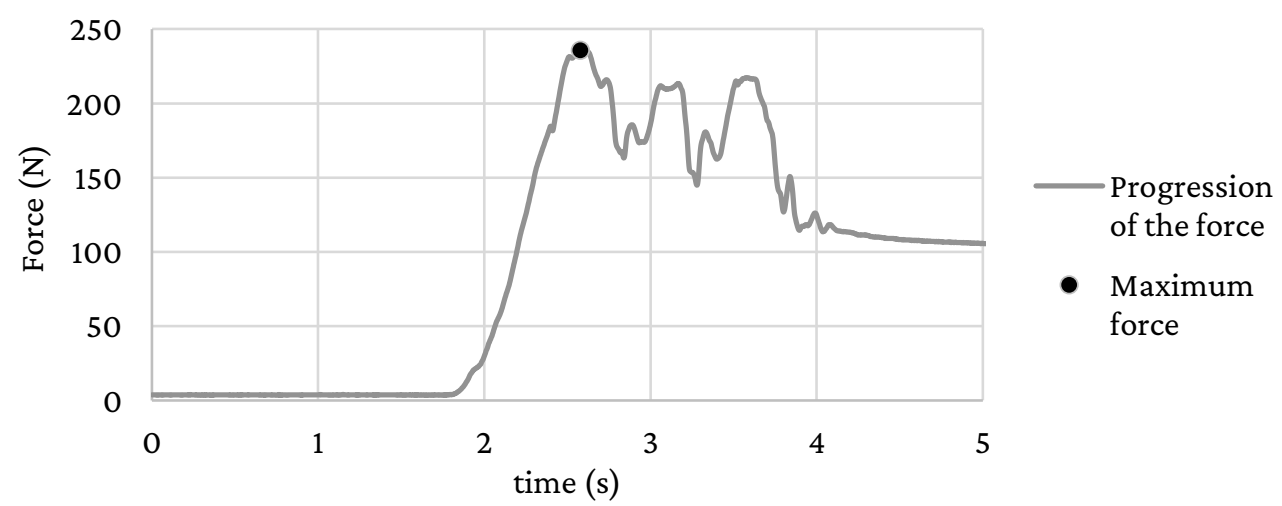

Figure 13: Experimental investigation of the slippage behavior caused by provoked overstress

drive can be achieved in the narrow installation space. Due to the coefficient of friction of 0.2 achieved by the textile mat support and the support by renewable materials, a maximum load to be moved per toothed belt pair of $4000 \mathrm{~N}$, about $407 \mathrm{~kg}$, can be realized.

The limit of the system becomes apparent in case of overstrain. In this case slip occurs, so that when the clamping force and holding force between the toothed belts is exceeded, the carriers slide through until the corresponding carriers meet the next pair of magnets on the toothed belts. This results in a swelling power transmission. In the illustration this is provoked with a fixed mat chain and the absorption of the transmitted pulling force.

\section{Sliding Support}

For a possible optimization of the transmittable force from the drive to the mat chain, research was carried out on the friction pairing. Alternative materials to the state of the art were searched for in order to reduce the occurring frictional forces. In the state of the art, mainly engineering plastics or metallic materials are used as a plate for a sliding plane. The research work carried out was focused on the use of textile gliding planes and sliding planes using renewable materials such as wood. Plywood from birch veneer was investigated. Plywood covered with phenolic resin was investigated. The smooth phenolic resin coating 


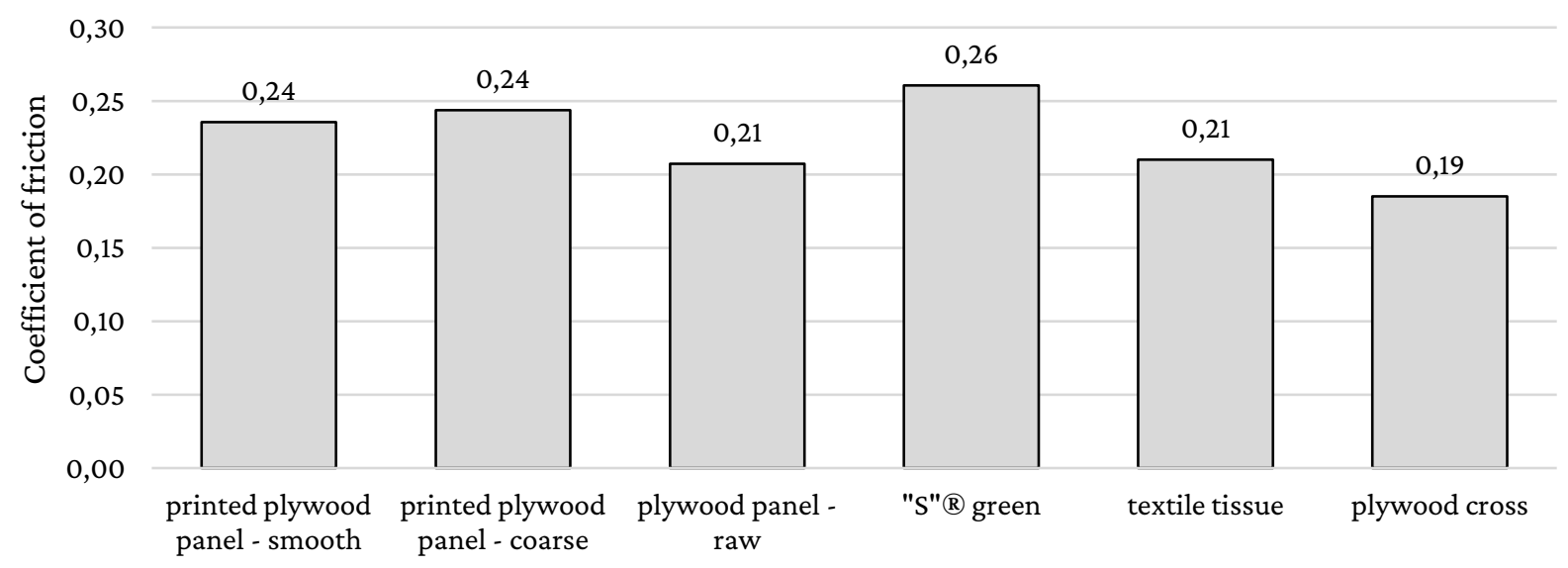

Figure 14: Coefficients of friction between the mat chain material and selected partners

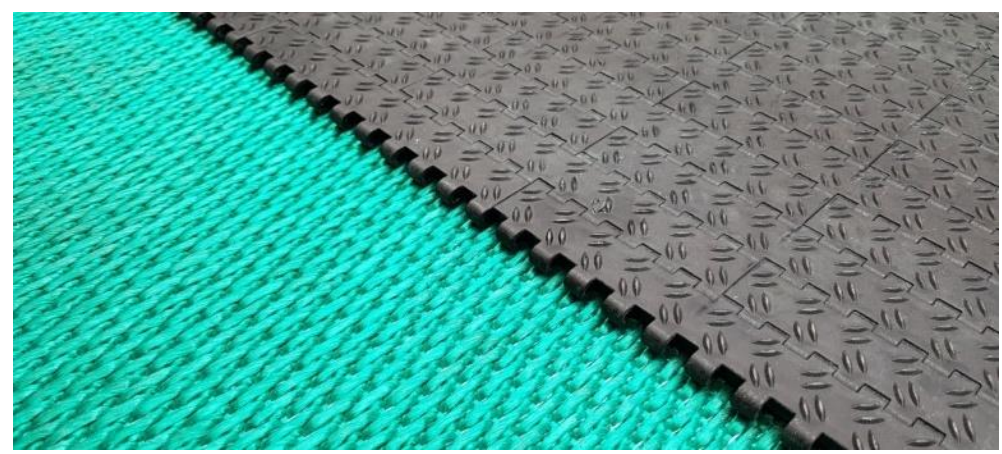

Figure 15: Textile sliding support with mat chain running on it [6]

(smooth), the raw wood surface (raw), the coated plywood (coarse) and the vertically placed

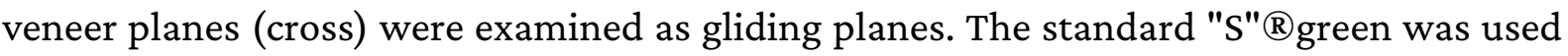
for comparison. The textile variant consisted of the preferred tissue TU2 (Figure 15), which was developed with the company Mr. Snow $\mathrm{GmbH}$ in cooperation with the Technical University of Chemnitz. The preferred fabric with the Panama binding consists of polypropylene (PP-NE591). The fineness of the yarn is 20.000 dtex and the number of cross threads is 230 per meter with a weft density of 350 threads per meter. [6]

\section{Total System}

The complete system of a long flat continuous conveyor without critical transfer points with the frame and drive as well as the mat chain with the carriers was successfully developed and implemented by the mechanical engineering company HELLWIG Förder- und Transporttechnik GmbH in cooperation with the Chemnitz University of Technology Professorship of Material Handling and Conveying Engineering 


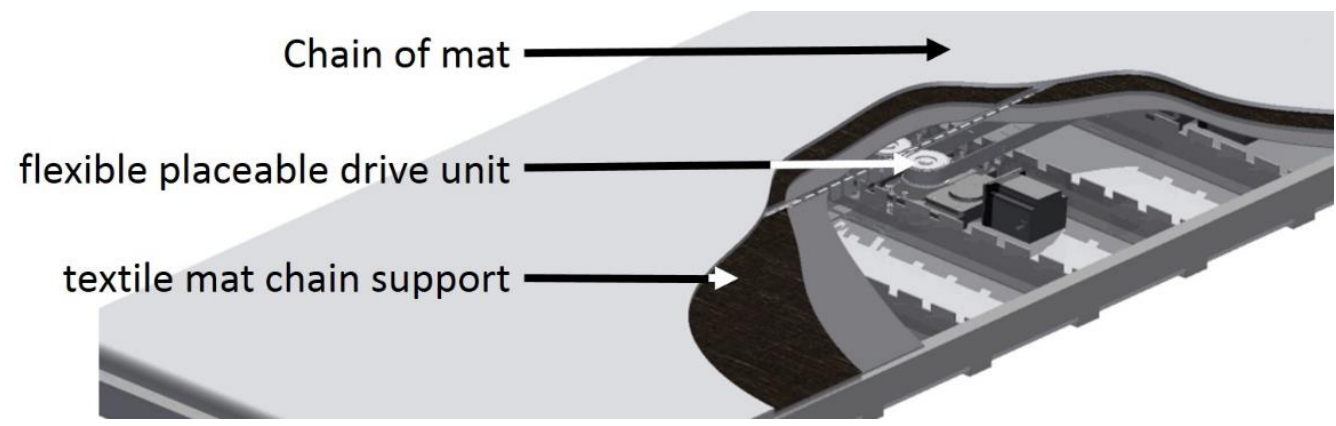

Figure 16: Schematic representation of the system with the textile sliding support
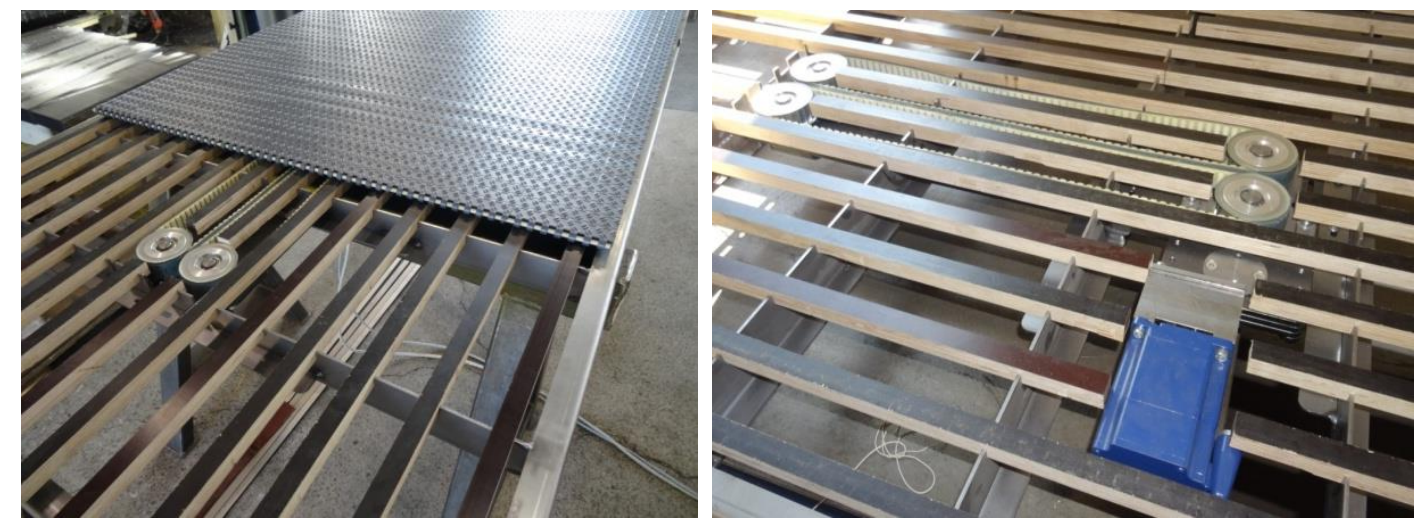

Figure 17: Installed drive with open mat chain

\section{Acknowledgement}

The research project UfDi - "Ultra-flat direct drive" with the funding code ZF4018635LP7, ZF4399001LP7 and the "Flat, textile support of belt-shaped traction and suspension means for continuous conveyors" with the funding code ZF4018624PK6 were funded by the Central Innovation Programme of the Federal Ministry of Economics and Technology (ZIM).

\section{References}

[1] Hambacher, S.: 2009, Der Trommelmotor- Das Multitalent moderner Stückgut-Fördertechnik, Springer Vieweg, 2019, ISBN 978-3-662-59007-2

[2] Sumpf, J.: Lecture: Basics of conveyor technology, belt conveyors, TU Chemnitz, 2016, p 24ff

[3] Product Catalogue from MayTec, Produktuebersicht_1_2019.pdf, 10.10.2020

[4] Nendel, K.; Drechsler, F.: Magnetic timing belts for direct drives in materials handling. In: 16th conference "Tooth belt drives" at ifte, p.57-67, 2012

[5] Subbert, S.; Nendel, K.; Meynerts, P.: Disclosure document DE 102009052985 A1 Bezeichnung Fördereinrichtung, 2009

[6] Weise, Sebastian; Penno, Eric; Golder, Markus: Textile Gleitabstützung für flache, direktangetriebene Stetigförderer, Conference fee, Technomer 2019: 26. Fachtagung über Verarbeitung und Anwendung von Polymeren, 2019 